\title{
Accelerations in the Local Magnetic Field on the Adriatic Tectonic Microplate
}

\author{
Rudi Čop ${ }^{1}$, Jean L. Rasson², Andrej Bilc ${ }^{3}$ \\ ${ }^{1}$ Institute Terra Viva, Sečovlje, Slovenia \\ ${ }^{2}$ Royal Meteorological Institute, Dourbes, Viroinval, Belgium \\ ${ }^{3}$ 2B Geoinformatika, Ljubljana, Slovenia \\ Email: rudi@artal.si
}

How to cite this paper: Čop, R., Rasson, J.L. and Bilc, A. (2021) Accelerations in the Local Magnetic Field on the Adriatic Tectonic Microplate. Open Journal of Earthquake Research, 10, 95-104. https://doi.org/10.4236/ojer.2021.103007

Received: June 29, 2021

Accepted: August 14, 2021

Published: August 17, 2021

Copyright (c) 2021 by author(s) and Scientific Research Publishing Inc. This work is licensed under the Creative Commons Attribution-NonCommercial International License (CC BY-NC 4.0). http://creativecommons.org/licenses/by-nc/4.0/ (c) (i) (8) Open Access

\begin{abstract}
The high level of noise is a special feature of the geomagnetic field on the territory of Slovenia. The tension of the Adriatic tectonic microplate, on which Slovenia entirely lies, was recognized as one of its sources. The interior of the Earth is also the source of geomagnetic jerks. They are impulses in the secular variation calculated on the basis of monthly or annual mean values of variation of the geomagnetic field. The paper presents an analysis of accelerations in a local magnetic field calculated on the bases of daily mean values of the magnetic field measured at PIA geomagnetic Observatory (Piran, Slovenia) in 2020. These accelerations indicate geomagnetic impulses at the regional level over days or weeks. Then these results are compared with the registered seismic activity in the West Balkans.
\end{abstract}

\section{Keywords}

Geomagnetic Observatory, Geomagnetic Jerks, Accelerations in the Local Magnetic Fields, Seismic Activity

\section{Introduction}

In 2014 the observatory was built on the edge of the village of Sv. Peter above River Dragonja in the Slovenian part of Istria $\left(45.459^{\circ} \mathrm{N}, 13.685^{\circ} \mathrm{E}, \mathrm{H}=196 \mathrm{~m}\right)$. After the international organization IAGA (International Association of Geomagnetism and Aeronomy), it has international code PIA (Piran, Slovenia) (hereinafter: the Observatory). We have been systematically looking for a suitable place to set up such an observatory since 2007 [1]. The method of its construction was mainly influenced by the presence of atmospheric electrical discharges [2], as well as the choice of its measuring instruments [3], which was specially adapted 
to the conditions in this area. The Observatory is located in the southwestern part of Slovenia, in the area with the highest annual density of lightning in Europe [4]. In addition to atmospheric discharges, it is also affected by vandalism, forest fires and floods due to surface waters. It is situated in a Natura 2000 area [5] and is not protected by a fence. This direct contact with nature allows us to monitor changes therein.

The setting up of the Observatory was most influenced by the general state of affairs in the society for which such an observatory is intended. International recommendations [6] and our experiences with the first geomagnetic observatory, SNV Observatory at Sinji vrh above Ajdovščina, were of great help in finding another additional site in Slovenia. The site of the SNV Observatory was $52.6 \mathrm{~km}$ from the PIA Observatory with the azimuth of 21.5 angular degrees.

On 20 May 2012, an unexpected change in the local magnetic field was measured at Sinji vrh. At that time we were just testing the magnetometer, so the measurement results have not been converted into real units of measurement and with a time delay of two hours. A detailed analysis of this event showed that the registration took place during a strong earthquake with magnitude $\mathrm{M}_{\mathrm{L}}=5.1$ (Richter earthquake scale) and with the epicenter near the city of Bologna in Italy. The change in all three components of the magnetic field (Figure 1) was very similar to the record of the seismograph [7]. The epicenter was $260 \mathrm{~km}$ from the measurement site with the azimuth 216.7 angular degrees. The registration itself was done with a three-axis fluxgate magnetometer that was not made for seismic zones because its sensor was suspended. That is why we chose a different type of magnetometer for the Observatory in Sv. Peter. The Slovenian part of Istria is built of flysch. The layer of hard limestone translates into seismic waves very well. For this reason, the sensor of the magnetometer was placed on a measuring pillar in a soft layer of sandstone, which is not a standard solution [8]. For the expected maximum amplitudes of seismic waves in the Observatory area, such a solution proved to be the right one. Earthquakes do not move the magnetometer sensor and therefore the measuring instrument for measuring changes of the magnetic field does not act as a seismograph (Figure 1). Therefore, even during an earthquake, it actually measures only changes in the magnetic field [9].

\section{Greater Level of Noise in the Local Magnetic Field}

The geomagnetic field on the territory of Slovenia contains a larger amount of noise than on the territory of neighboring countries. In July 2015 the SNV Observatory was still in function. At that time the nearest geomagnetic observatory with a long tradition was the TYH Observatory (Tihany, Hungary) [10]. A comparison of the measured values in last three hours 3 July 2015 shows that the noise level at the PIA Observatory is $38 \%$ higher than the level at the TYH Observatory. This level is increasing from the Adriatic coast towards the interior of Slovenia, so that at the SNV Observatory it is already $20 \%$ higher than at the PIA Observatory (Figure 2). 


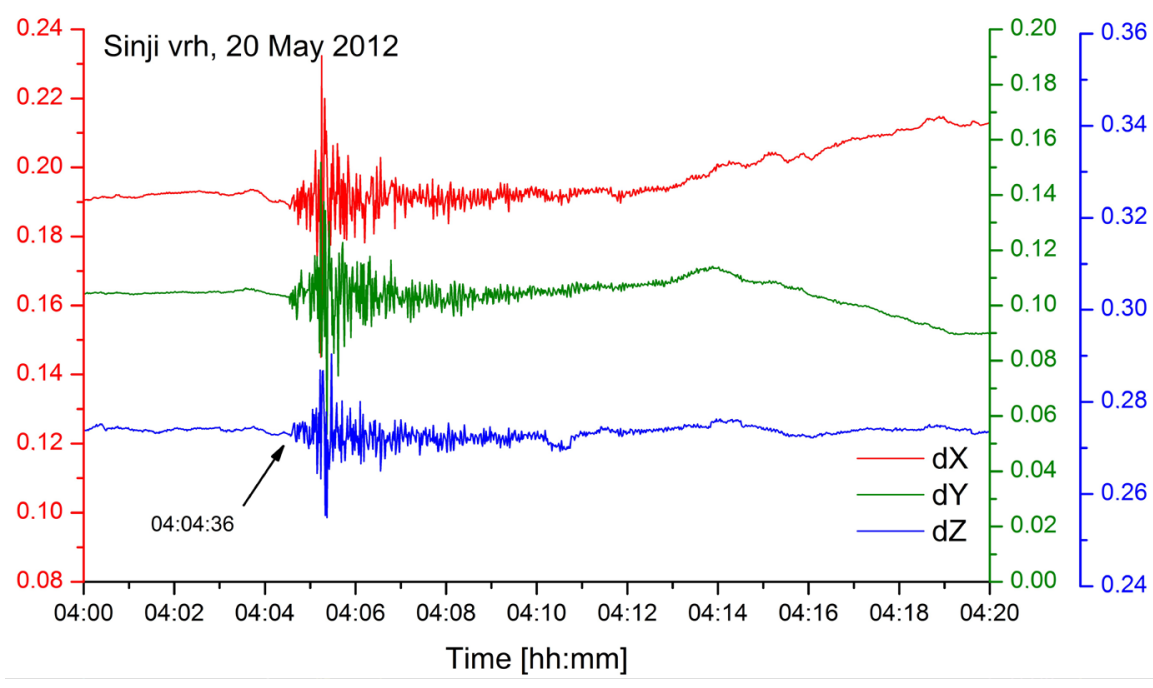

Figure 1. Measuring of the change in the local magnetic field at Sinji vrh above Ajdovščina during earthquake in Bologna (Italy) on 20 May 2012. Graf presents the variations of all three orthogonal components X (north), Y (east) and Z (nadir) of the geomagnetic field.

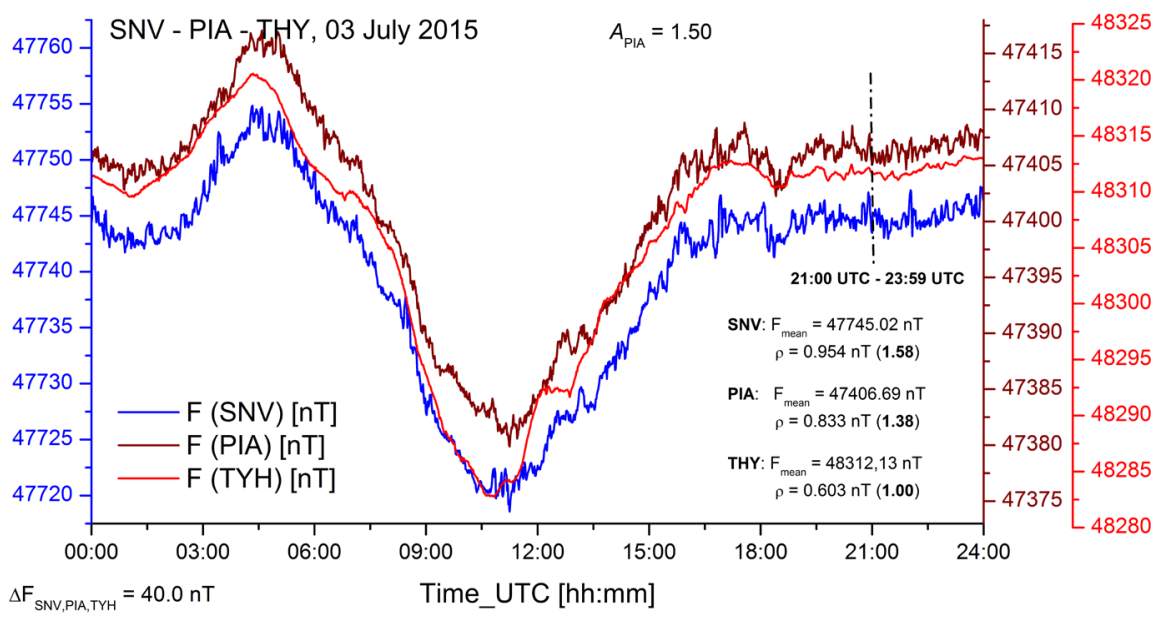

Figure 2. Magnetograms of the geomagnetic field density $F[\mathrm{nT}]$, drawn on the basis of measurements on 3 July 2015, at the SNV (Sinji vrh, Slovenia), PIA (Piran, Slovenia) and TYH (Tihany, Hungary) Observatories.

The geomagnetic field on the territory of Slovenia contains noise in component $Z$, which in the northern hemisphere acts vertically downward and in component $X$, which acts in the direction of the geographical pole (south-north) [11]. As this noise is a special feature of the Slovenian territory, we first had to verify the low noise level of the initial measuring instrument-an Oberhauser proton magnetometer [12] and then make comparative measurements at five locations with approximately the same distance along the same longitude from the location of the Observatory near the Adriatic coast to the middle of the country. In doing so, we found that the calmest area in Slovenia is on the edge of the Slovenian part of Istria. This was not shown by the GIS (geographic information 
system) analysis [6] or by the preliminary measurements [13].

The initial study of atmospheric discharges [3] was followed by the study of the influence of transitions of weather fronts on the local magnetic field [14] and artificial sources of noise in the magnetic field [15] [16]. The influence of the Moon could be studied in more detail only during the solar minimum at the transition from the 24th to the 25th solar cycle [17]. Knowing those influences allows us to exclude them from further processing of measurement data of the change of the local magnetic field.

Any relative changes in the energy density in the Earth's magnetic field due to changes in tectonic stresses are very small-they are part of the noise. They can be evaluated on the basis of changes in the energy of the Earth's magnetic field between individual days [18]. The energy density in the magnetic field is determined by Equation (1), which also applies to the energy density in the geomagnetic field $w_{G M}$.

$$
w_{G M}=\frac{W}{V}=\frac{1}{2 \mu_{0}} B^{2}
$$

In Equation (1) are:

- $W$ : energy in the magnetic field;

- V: volume;

- $\mu_{0}$ : magnetic permeability of free space;

- $B$ : magnetic flux density.

Two to three days before an earthquake occurs, the energy density in the local magnetic field increases greatly, which could be used for a short-term earthquake prediction. But an increase in this density is not yet a serious indicator of an earthquake. When an earthquake does occur, the density of the earth's magnetic field is previously increased, but with an increased density, it is not necessary for an earthquake to occur.

\section{Geomagnetic Jerks}

Mathematical models of the change in the Earth's magnetic field on its surface rely on secular changes in the magnetic field, which are changes in its components over long periods of time. In shorter intervals, however, these changes are uneven and therefore cannot be predicted. The sources of all changes in the Earth's magnetic field are either inside of the Earth or in space. For geomagnetic jerks, the interior of the Earth is recognized as the place of their origin [19] [20]. Recent theoretical research suggests that they result from irregularities in the flow of the Earth's liquid core [21] [22]. Hydrodynamic waves in the form of torsional oscillations are formed in its outer core. They are caused by bubbles that travel slowly towards the outer edge of the area of convection currents, interfering with their normal flow [23]. The consequences of this uneven flow in the outer core are various geophysical phenomena: small deviations of the Earth's rotational axis with respect to land surface (Chandler wobble) and change in its speed with associated change in its climate [19]. There is also the possibility that 
geomagnetic jerks are the cause of stronger earthquakes and vice versa [24] [25].

Periods of secular changes in which the changes are constant are interconnected by geomagnetic jerks. In the graph of the secular changes of the geomagnetic field geomagnetic jerks are noticed as sudden changes in the shape of the letter V. They were first described in the 1970s [26]. Some of them occur only in a limited area of the Earth's crust, such as individual continents or only parts of them, and occur every few months or years. But there are also those that are registered everywhere on the globe and happen unannounced every ten years on average.

In general, impulses are a sudden change in the form of an increase or decrease in a more or less uniform change in the observed phenomenon. Geomagnetic impulses or jerks are sudden changes that defined in the value of at least the first derivation of the time in the secular change of the Earth's magnetic field [27]. Each of the components of the Earth's magnetic field can be described in a second-degree polynomial Equation (2). In this polynomial equation geomagnetic jerks are recognized as a change in its coefficients. The closer these changes approach the shape of the letter $\mathrm{V}$, the more the first derivation of the time is equal to the step and the second derivation of the time is equal to the pulse.

$$
\begin{gathered}
y(\mathrm{t})=A+B t+C t^{2} \\
\dot{y}=B+2 C t \\
\ddot{y}=2 C
\end{gathered}
$$

Geomagnetic jerks of a global nature have been investigated using both frequency analysis [28] and wavelet analysis [29]. For the individual observatories the initial research was conducted on the bases of annual mean values of measurements, from which the temperature drift of electronic measuring instruments is eliminated. Research of the geomagnetic jerks has improved the understanding of the mechanisms that take place inside the Earth. Measurements of the geomagnetic field with the help of state-of-the-art purpose build satellites have improved this understanding [30].

\section{Accelerations in the Local Magnetic Field}

The graph of mean daily values of the magnetic field, determined directly from measurements of magnetometers on the Observatory, shows that the strength of the local magnetic field $F(t)[\mathrm{nT}]$ in 2020 was constantly increasing (Figure 3 ). A larger number of sudden changes are also visible. The acceleration of the change in magnetic field strength is represented by the second derivative $\mathrm{d}^{2} F(t)$ $\left[\mathrm{nT} / \mathrm{day}^{2}\right]$. The value of this derivative in the whole of 2020 exceeded the value of $6.0 \mathrm{nT} /$ day $^{2} 24$ times, of which twice $12.0 \mathrm{nT} /$ day $^{2}$ : the 34th day (March 22, 2020) and the 340th day (December 28, 2020).

The MSA (Mean Square Amplitude) algorithm was used for spectral analysis of FFT (Fast Fourier Transform) above the daily mean values of the local magnetic 


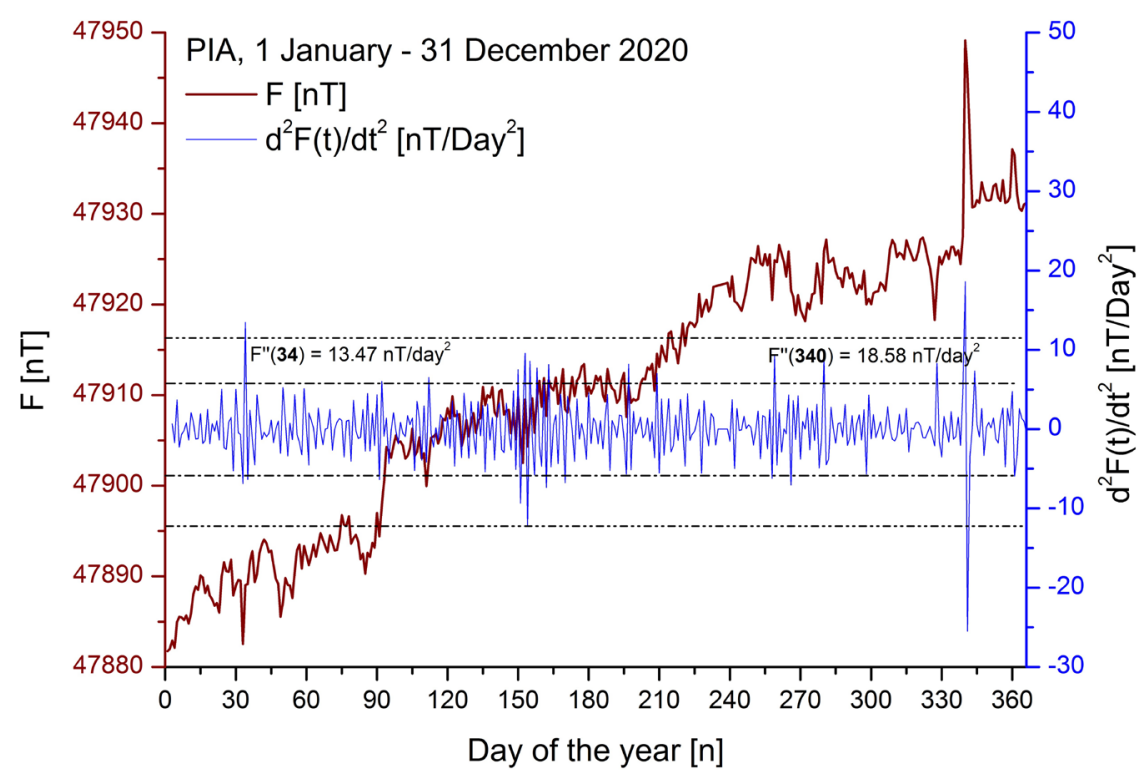

Figure 3. Graph of daily mean values of the local magnetic field $F(t)$ and its second derivative $\mathrm{d}^{2} F(t)$ in Slovenia in 2020 .

field in 2020 measured on the Observatory. The properties of this selected algorithm for conversion from time space to frequency space must be taken into account when analyzing the results obtained. After contributing to the spectral power density, the periods are divided into two consecutive groups (Figure 4). They are separated by a period of 14.07692 days, which is about half of the lunar month, which lasts an average of 29.53059 days. Equation (1) for the energy density in a magnetic field also proves that these two groups exist if the polynomial Equation (2) is replaced in it instead of the magnetic field density.

In 2020, seismographs of the national network of seismic observatories of the Republic of Slovenia registered 555 local earthquakes with a magnitude of $M_{L} \geq$ 1 or an average of 1.5 earthquakes/day [31]. Local earthquakes are all earthquakes that have their epicenter on the territory of Slovenia $\left(20,271 \mathrm{~km}^{2}\right)$ or in its immediate vicinity. An earthquake occurs in its immediate vicinity if its epicenter is not more than $50 \mathrm{~km}$ from the nearest populated area in Slovenia.

The year 2020 was marked by two major earthquakes. The first occurred on the 82nd day (March 22, 2020) in Zagreb with the largest magnitude $M_{L}=5.5$ [32], and the second one on the 363rd day (December 28, 2020) near Petrinja with the largest magnitude $M_{L}=6.2$ [33]. Both earthquakes were on the territory of the neighboring Republic of Croatia. On December 28, 2020 there were no local earthquakes in Slovenia. For this reason the earthquake in Petrinja is only marked with $m=70$ earthquakes/day (Figure 5).

\section{Discussion}

For a period of a few days, the power contribution of all the periods that make up the year-round change in the mean daily values of the local magnetic field is negligibly small. The transition to the part with larger amplitudes is at a period 


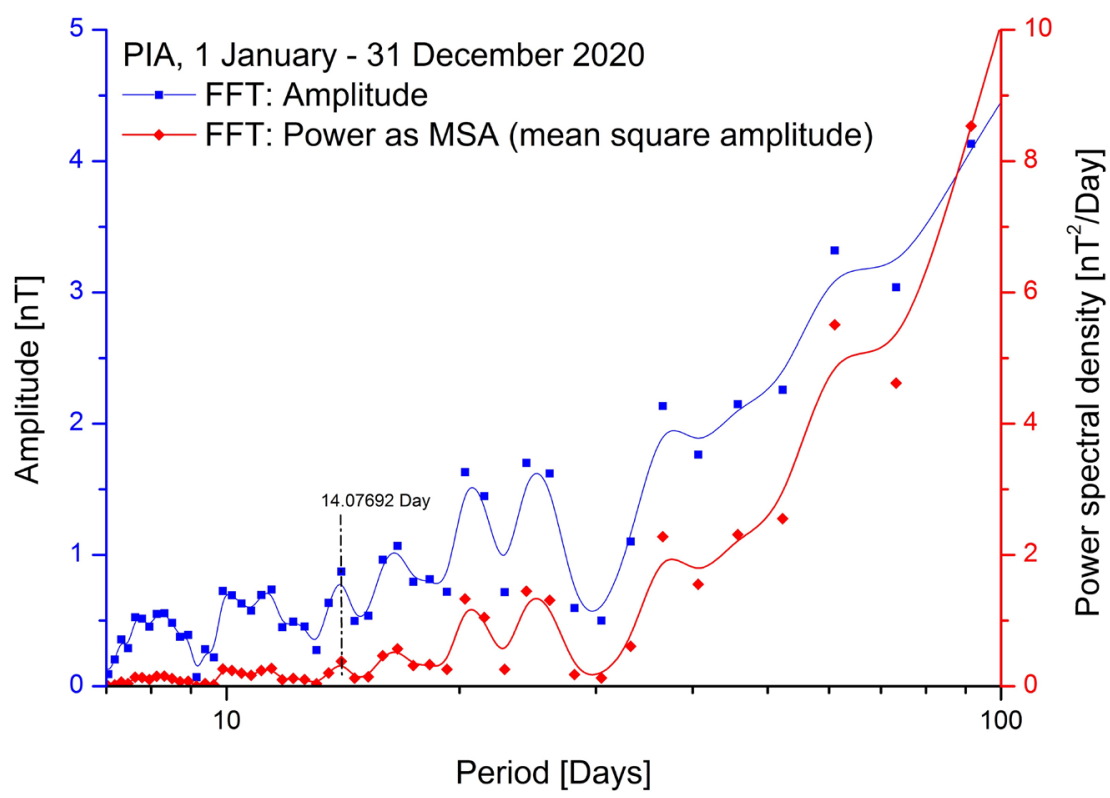

Figure 4. Sequence of periods of less than 100 days or 0.27 years obtained by spectral analysis of FFT above the mean daily values of the local magnetic field $F(t)$ [nT] in 2020 . Due to a better presentation of the obtained results of conversion into frequency space, these are fitted together with the Basis spline (B-spline).

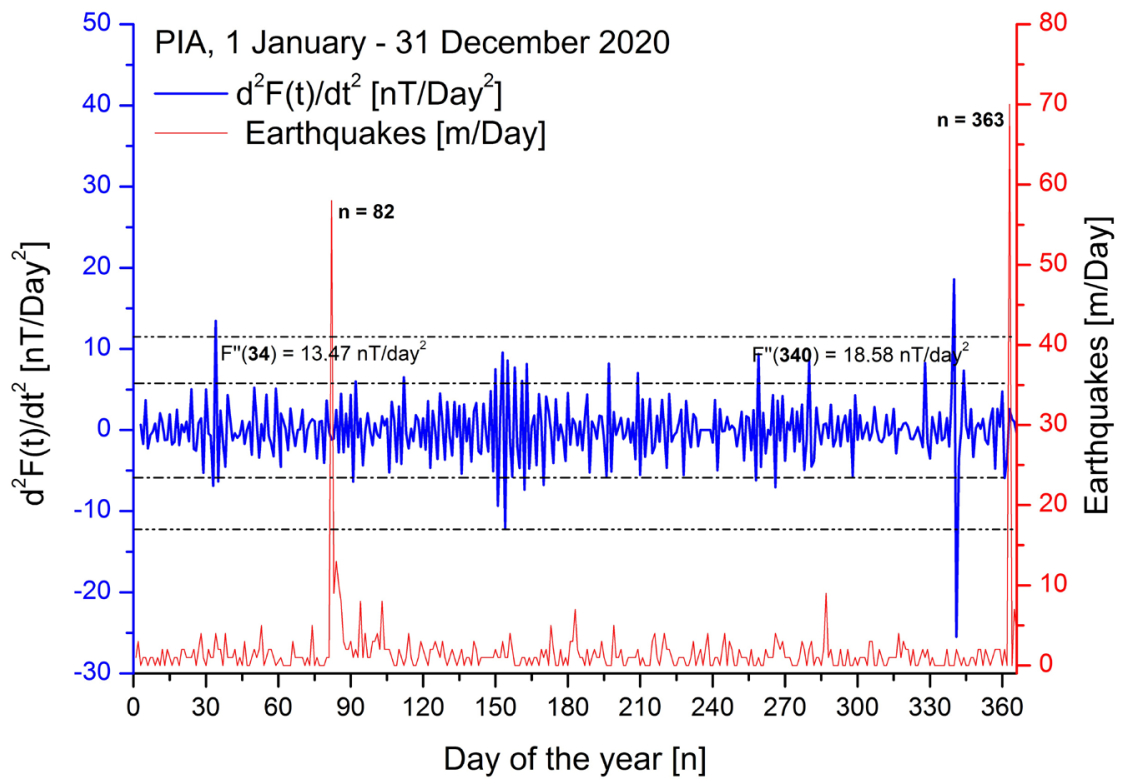

Figure 5. Graph of the second derivative $\mathrm{d}^{2} F(t)$ of daily mean values of the local magnetic field $F(t)$ and the number of local earthquakes in Slovenia in 2020.

of the half of the lunar month (Figure 4). The period of 7.4 days or the mean length of each lunar phase is very poorly presented in the power spectrum. Further research would be needed to confirm the link between the gravitational influence of the Moon and geophysical phenomena associated with accelerations in the local magnetic field. The sequence of period pairs indicates the pulsation generated by frequencies longer than one year. Therefore, eventual further re- 
search for additional confirmation the findings presented in this article, should cover a period of at least a few years.

In 2020, no major earthquake occurred on the territory of Slovenia, but there were two strong earthquakes on the territory of neighboring Croatia. The first one occurred 48 days after the appearance of the first large impulses in the geomagnetic field with acceleration greater than $12.0 \mathrm{nT} /$ day $^{2}$ was earthquake with local characteristic. The second one, 23 days after the second such large impulse in 2020, was earthquake with regional characteristic. Therefore, we find that all the geophysical phenomena related to accelerations in local magnetic field should be observed on a wider territory than that of Slovenia.

\section{Conclusion}

Reliable earthquake prediction would be desirable, but it will only be possible if we first develop appropriate algorithm and test it on a limited territory. The algorithm should be based on different measurements, which arise from different physical principles. Among them seismological measurements would be basic. The said territory should be a seismological and tectonically limited area without volcanic activity such as the Adriatic tectonic microplate. Only the algorithm with great reliability could eventually be applied to outer areas of the world.

\section{Acknowledgements}

The authors would like to thank all those who, as volunteers, helped set up and maintain the PIA Observatory. We would also like to thank all those who help write this article on behalf of the professional journal OJER.

\section{Conflicts of Interest}

The authors declare no conflicts of interest regarding the publication of this paper.

\section{References}

[1] Čop, R., Deželjin, D., Mihajlović, J.S. and Kosovac, P. (2011) Preliminary Measurements of Geomagnetic-field Variations in Slovenia. Elektrotehniški Vestnik (English Edition), 78, 96-101. https://ev.fe.uni-lj.si/3-2011/Cop.pdf

[2] Flux-Gate Magnetometer LEMI-022 SI (2014) User Manual, KMS Technologies, Laboratory for Electromagnetic Innovations, Lviv.

[3] Čop, R., Milev, G., Deželjin, D. and Kosmač, J. (2014) Protection against Lightning at a Geomagnetic Observatory. Geoscientific Instrumetation, Methodes and Data Systems, 3, 135-141. https://doi.org/10.5194/gi-3-135-2014

[4] Anderson, G. and Klugmann, D. (2014) A European Lightning Density Analysis Using 5 Years of ATDnet Data. Natural Hazards and Earth System Sciences, 14, 815-829. https://doi.org/10.5194/nhess-14-815-2014

[5] Petkovšek, M. (2015) Vzpostavljeno omrežje Natura 2000. Establishment of the Natura 200 Network. Varstvo Narave, 28, 41-61.

[6] Paliska, D., Čop, R., Fabjan, D. and Drobne, S. (2010) Izbira lokacje za postavitev geo- 
magnetnega observatorija v Sloveniji. Site Selection a Permanent Geomagnetic Observation Station in Slovenia. Geodetski Vestnik, 54, 469-480.

[7] Dolce, M., Nicoletti, M., Ammirati, A., Bianconi, R., Filippi, L., Gorini, A., Marcucci, S., Palma, F., Zambonelli, E., Lavecchia, G., De Nardis, R., Brozzetti, F., Boncio, P., Cirillo, D., Romano, A., Costa, G., Gallo, A., Tiberi, L., Zoppe, G., Suhadolc, S., Ponzioni, F. and Formica, A. (2012) The Emilia Thrust Earthquake of 20 May 2012 (Northern Italy): Strong Motion and Geological Observation. Report 1. Presidenza Del Consiglio Dei Ministeri, Dipartimento Della Protezione Civile: DPC (National Civil Protection Department), Roma.

[8] Jankowski, J. and Suckdorff, C. (1096) Guide for Magnetic Measurements and Observatory Practice. International Association of Geomagnetism and Aeronomy, Boulder.

http://www.iaga-aiga.org/data/uploads/pdf/guides/iaga-guide-observatories.pdf

[9] Čop, R. (2017) Spremembe gostote energije v zemeljskem magnetnem polju. The Elektrotehniški Vestnik, 84, 148-154. https://ev.fe.uni-lj.si/4-2017/Cop.pdf

[10] Csontos, A., Hegymegi, L., Heilig, B., Kovacs, P., Merenyi, L. and Szabo, Z. (2007) 50 Years of History of the Tihany Geomagnetic Observatory. Publications of the Institute of Geophysics, Polish Academy of Sciences, C-99, 32-37.

[11] Campbell, H. W. (2003) Introduction to Geomagnetic Fields. 2nd Edition, Cambridge University, Cambridge. https://doi.org/10.1017/CBO9781139165136

[12] Čop, R. and Kosovac, P. (2010) Preliminary Measurements of the Overhauser Proton Magnetometer. Raziskave s področja geodezije in geofizike 2009. Zbornik del. Fakulteta za Gradbeništvo in Geodezijo, Ljubljana, 23-29.

[13] Čop, R. and Kocen, J. (2009) Geomagnetic Measurements at the Geomagnetic Reference Point at Predmeja. Raziskave s področja geodezije in geofizike 2008. Zbornik del. Fakulteta za Gradbeništvo in Geodezijo, Ljubljana, 69-78.

http://fgg-web.fgg.uni-lj.si/SUGG/referati/2009/SZGG09_Cop_Kocen.pdf

[14] Čop, R. (2015) Snowstorm at the Geomagnetic Observatory. Geoscientific Instrumentation, Methods and Data Systems, 4, 155-159. https://doi.org/10.5194/gi-4-155-2015

[15] Čop, R. and Henigman, F. (2018) An Electromagnetic Wave Receiver at Frequency beyond $50 \mathrm{~Hz}$. Elektrotehniški Vestnik, 84, 155-161.

https://ev.fe.uni-lj.si/4-2018/Cop.pdf

[16] Čop, R. (2018) ELF Receiver for EM Waves beyond $46 \mathrm{~Hz}$. Conrad Observatory Journal, 5, 11.

https://conrad-observatory.at/index.php/downloads-en/category/5-cobsjournal

[17] Kuhar, M., Čop, R. and Pavlovčič Prešeren, P. (2020) The Influence of the Moon on Geomagnetic Noise. Geodetski Vestnik, 64, 303-319.

https://doi.org/10.15292/geodetski-vestnik.2020.03.303-319

[18] Pavlovčič Prešeren, P., Čop, R. and Kuhar, M. (2020) The Use of Geomagnetic Measurements to Study Local Tectonic: Case for the NE Part of Adria-Eurasia Collision Zone. Open Journal of Earthquake Research, 9, 83-99. https://doi.org/10.4236/ojer.2020.92006

[19] De Michelis, P., Tozzi, R. and Meloni, A. (2005) Geomagnetic Jerks: Observation and Theoretical Modeling. Memorie Della Societa Astonomica Italiana, 76, 957-960.

[20] Meloni, A., Caafarella, L., De Michelis, P. and Tozzi, R. (2007) The Contribution of Geomagnetic Observatories and Magnetic Model to Study of Secular Variation and Jerks in Antarctica. USGS OF-2007-1047, Short Research Paper 071. U.S. Geological Survey and the National Academies. https://pubs.usgs.gov/of/2007/1047/srp/srp071/of2007-1047srp071.pdf 
[21] Le Huy, M., Mandea, M., Le Mouel, J.-L. and Pais, A. (2000) Time Evolution of the Fluid Flow at the Top of the Core. Geomagnetic Jerks. Earth Planet Space, 52, 163-173. https://doi.org/10.1186/BF03351625

[22] Ballani, L., Hagedoorn, J., Wardinski, I., Stromeyer, D. and Greiner-Mai, H. (2010) The 1991 Geomagnetic Jerks as Seen at the Earth's Surface and the Core-Mantle Boundary. Geophysical Journal International, 183, 659-680. https://doi.org/10.1111/j.1365-246X.2010.04787.x

[23] Aubert, J. and Finlay, C.C. (2019) Geomagnetic Jerks and Rapid Hydromagnetic Waves Focusing at Earth's Core Surface. Nature Geoscience, 12, 393-398. https://doi.org/10.1038/s41561-019-0355-1

[24] Florindo, F., Alfonsi, L., Piersanti, A., Spada, G. and Marzocchi, W. (1996) Geomagnetic Jerks and Sezmic Activity. Annals of Geophysics, 39, 1227-1233.

https://doi.org/10.4401/ag-4049

[25] Florindo, F., De Michelis, P., Piersanti, A.and Boschi, E. (2005). Could the Mw $=9.3$ Sumatra Earthquake Trigger a Geomagnetic Jerks? Eos, Transactions American Geophysical Union, 86, 123. https://doi.org/10.1029/2005EO120004

[26] Courtillot, V. and Le Mouel, J.-L. (1976) On the Long-Period Variations of the Earth's Magnetic Field from 2 Months to 20 Years. Journal of Geophysical Research, 81, 2941-2950. https://doi.org/10.1029/JB081i017p02941

[27] Gavoret, J., Gilbert, D., Menvielle, M. and Le Mouel, J.-L. (1986) Long-Term Variations of the External and Internal Components of the Earth's magnetic Field. Journal of Geophysical Research; Solid Earth, 91, 4787-4796.

https://doi.org/10.1029/JB091iB05p04787

[28] Duka, B., De Santis, A., Mandea, M. and Isac, A. Qamili, E. (2012) Geomagnetic Jerks Characterization via Spectral Analysis. Solid Earth, 3, 131-148. https://doi.org/10.5194/se-3-131-2012

[29] Pinheiro, J.K. and Travassos, M.J. (2010) Impulses of the Geomagnetic Secular Variation (Jerks) at Vassouras Magnetic Observatory Detected by Wavelet Analysis. RBGf. Revista Brasileira de Geofisica, 28, 37-46. https://doi.org/10.1590/S0102-261X2010000100003

[30] Brown, W., Beggan, C. and Macmillan, S. (2016) Geomagnetic Jerks in the Swarm Era. British Geological Survey. The Lyell Centre, NERC Open Research Archive, Edinburgh. http://nora.nerc.ac.uk/id/eprint/514296/1/1547brown.pdf

[31] Earthquakes-Archive of Notifications of Recent Earthquakes (2021) Ministry of the Environment and Spatial Planning, Slovenian Environment Agency, Ljubljana. https://www.arso.gov.si/potresi/potresi_arhiv.html

[32] Markušić, S., Stanko, D., Korbar, T., Belić, N., Penva, D. and Kordić, B. (2020) The Zagreb (Croatia) M5.5 Earthquake on 22 March 2020. Geosciences, 10, 252. https://doi.org/10.3390/geosciences10070252

[33] Markušić, S., Stanko, D., Penva, D., Ivančić, I., Bjelotonić Oršulić, O., Korbar, T. and Sarhosis, V. (2021) Destructive M6.2 Petrinje Earthquake (Croatia) in 2020-Preliminary Multidisciplinary Research. Remote Sensing, 13, 1095.

https://doi.org/10.3390/rs13061095 